\title{
A POTENCIALIDADE DO MÉTODO VIVÊNCIAS NA NATUREZA PARA A EDUCAÇÃO AMBIENTAL
}

Patrícia Angela Grisa de Assis ${ }^{1}$

Jane Márcia Mazzarino²

Resumo: $O$ objetivo do estudo foi investigar a potencialidade do método Vivências na Natureza, de Joseph Cornell, para processos de Educação Ambiental. O estudo delimitou-se à Escola Estadual Barão de Parima, de Boa Vista, Roraima. Trata-se de uma pesquisa qualitativa, com levantamento bibliográfico e pesquisa de campo, a qual incluiu questionários e entrevistas semiestruturadas e o desenvolvimento de atividades vivenciadas, visando a um contato mais próximo com a natureza. Concluiu-se que o método proporcionou envolvimento e sensibilização dos alunos, fortalecendo e ressignificando suas relações com a natureza e com o grupo, portanto as vivências potencializaram o processo de Educação Ambiental.

Palavras-chave: Educação Ambiental; Vivências na Natureza; Ensino Fundamental; Método Qualitativo. 


\section{Introdução}

A discussão a respeito da temática ambiental tem se ampliado consideravelmente no contexto internacional e brasileiro. A escola torna-se um espaço privilegiado para estabelecer relações e obter informações a esse respeito, criando condições e alternativas que estimulem a percepção do aluno como parte do meio ambiente.

A escola é um espaço fundamental para o desenvolvimento de valores, atitudes, conhecimentos e possibilidades comprometidas com a sustentabilidade ecológica e social, o que hegemonicamente se pressupõe que seja o foco dos processos de Educação Ambiental.

Tendo-se definido que se realizaria um estudo sobre a Educação Ambiental em um espaço formal, surgiu o questionamento se as vivências na natureza podem potencializar ressiginificações sobre as relações com o meio ambiente e, se o fazem, que sentidos emergem deste tipo de experiência? Portanto, nesse estudo investigam-se os sentidos emergentes em processos de Educação Ambiental baseados na aplicação do método de vivências no meio natural, entre alunos do Ensino Fundamental.

O método é qualitativo, baseado nas pesquisas bibliográfica e de campo. O estudo foi realizado com alunos da Escola Estadual Barão de Parima, de Boa Vista, Roraima, região Norte do Brasil. A escola está situada às margens do Rio Branco, tem 320 alunos matriculados do $1^{\circ}$ ao 9o ano do ensino fundamental, nos turnos matutino e vespertino e conta com 52 funcionários, distribuídos na parte administrativa, pedagógica e de apoio. Este educandário mostrou-se adequado para o estudo de campo por estar localizado às margens do Rio Boa Vista e ter pais e alunos que moram no próprio bairro ou muito próximo.

\section{Educação Ambiental: pressupostos hegemônicos}

Pode-se dizer que por meio da Educação Ambiental é possível construir novas relações dos grupos sociais com o meio ambiente. Inicialmente a Educação Ambiental foi concebida como uma preocupação dos movimentos ecológicos com uma prática de conscientização capaz de chamar a atenção para a finitude e má distribuição no acesso aos recursos naturais. Buscava-se envolver os cidadãos em ações sociais ambientalmente apropriadas. Em um segundo momento a Educação Ambiental vai se transformando em uma proposta educacional, com tradições, saberes e teorias próprias (CARVALHO, 2012).

A análise histórica da Educação Ambiental foi iniciada a partir de 1970, quando se institucionalizavam e intensificavam os debates sobre a problemática ambiental do mundo, sua relação com o desenvolvimento econômico e social das nações e com as mudanças de comportamento (SAITO, 2002). 
A Organização das Nações Unidas (ONU) promoveu, no ano de 1972, em Estocolmo a Conferência Mundial sobre Meio Ambiente, evento que foi um marco histórico e incluiu a necessidade de se investir em processos de Educação Ambiental para o enfrentamento dos problemas ambientais.

Daí em diante muitos outros encontros regionais, nacionais e internacionais aconteceram com o objetivo de discutir a relação entre sociedade e ambiente, quando se formularam propostas relacionadas à Educação Ambiental: Conferência de Belgrado, em Belgrado, lugoslávia, em 1975; Conferência Intergovernamental em Tbilisi, na Geórgia em 1977; Seminário sobre Educação Ambiental na Costa Rica, em 1979; Congresso Internacional sobre Educação e Formação Ambientais em Moscou, em 1987; Seminário Latinoamericano de Educação Ambiental na Argentina, em 1988; Conferência sobre Meio Ambiente e Desenvolvimento no Rio de Janeiro, Brasil, em 1992; Conferência Internacional sobre Meio Ambiente e Sociedade, Thessaloniki, Grécia, em 1997; Cúpula Mundial sobre Desenvolvimento Sustentável, Johanesburg, África do Sul em 2002; Conferência Internacional Rio + 15, no Rio de Janeiro em 2007; e a RIO+20 Conferência das Nações Unidas sobre o Desenvolvimento Sustentável, que aconteceu no Rio de Janeiro em 2012.

No Brasil, em 1988, foi promulgada a nova Constituição, que dedica um capítulo inteiro ao meio ambiente. Também significativas políticas públicas para a Educação Ambiental foram desenvolvidas no início da década de 1990. No ano de 1992, foram criados o Ministério do Meio Ambiente (MMA) e o Instituto Brasileiro de Meio Ambiente e de Recursos Naturais Renováveis (IBAMA) e o Ministério da Educação (MEC) criou os Centros de Educação Ambiental (BRASIL, 1998).

Com o evento denominado Rio 92 ou Eco 92 - Conferência das Nações Unidas sobre o Meio Ambiente e o Desenvolvimento (CNUMAD) foram oficialmente consolidados, por meio do Plano de Ação intitulado Agenda 21, compromissos entre as cúpulas de diversos países. Daí em diante muitas Agendas 21 foram construídas pelo mundo. Esse documento considera que a Educação Ambiental é indispensável para a modificação de atitudes, assim como para o desenvolvimento de comportamentos para a formação de uma sociedade sustentável.

Mas é o Tratado de Educação Ambiental para Sociedades Sustentáveis e Responsabilidade Global que estabeleceu princípios e um plano de ação para educadores ambientais. O documento é considerado fundamental para a Educação Ambiental brasileira e internacional e foi construído durante o Fórum Global 92, evento paralelo a Rio 92, do qual participaram cerca de 10 mil Organizações Não-Governamentais. A Carta da Terra também é resultado do Fórum.

Outro documento construído em 1992 foi a Carta Brasileira para a Educação Ambiental, que destacou a incumbência e compromisso não só do Estado, mas também das esferas estadual e municipal, quanto à incorporação 
e concretização de um trabalho de Educação Ambiental em todos os graus e modalidades de ensino, inclusive para a educação superior, que deve ofertar cursos de natureza interdisciplinar sobre questões ambientais.

Em 1991, através da Portaria oㅜ 678, de 14 de maio, o Ministério de Educação e Cultura (MEC) definiu que todos os currículos, nos diversos níveis de ensino, deviam contemplar conteúdos voltados à Educação Ambiental. Eles adotaram um caráter de transversalidade na estrutura curricular formal através dos Parâmetros Curriculares Nacionais - PCN's - criados em 1997. Neste documento, a Educação Ambiental é inserida na discussão do tema transversal "Meio Ambiente" tendo como principal função:

[...] contribuir para a formação de cidadãos conscientes, aptos a decidir e atuar na realidade socioambiental de um modo comprometido com a vida, com o bem-estar de cada um e da sociedade, local e global. Para isso é necessário que, mais do que informações e conceitos, a escola se proponha trabalhar com atitudes, com formação de valores, com o ensino e aprendizagem de procedimentos. E esse é um dos grandes desafios para a educação. Gestos de solidariedade, hábitos de higiene pessoal e dos diversos ambientes, participação em pequenas negociações são exemplos de aprendizagem que podem ocorrer na escola. (BRASIL, PCN's, 1997, p. 187).

Apesar das críticas que receberam pelo modo de pensar a transversalidade em educação e devido à baixa operacionalização da proposta, os PCN's tiveram seu mérito ao inserir a temática ambiental não como disciplina, mas sim de forma articulada às diversas áreas de conhecimento (LOUREIRO, 2004).

Em 1994, foi aprovado o Programa Nacional de Educação Ambiental ProNEA, que tinha como princípio que a Educação Ambiental deveria ser um dever constitucional do poder público, com o envolvimento da comunidade.

Por fim, a Educação Ambiental teve reconhecimento no cenário nacional brasileiro com a instituição da Política Nacional de Educação Ambiental (PNEA), Lei no 9795, aprovada em 1999 e regulamentada pelo Decreto no 4281 de 2002, a partir da qual foi institucionalizada a Educação Ambiental e foram legalizados seus princípios, transformando-a em um componente de políticas públicas (BRASIL, 1999).

Todos estes eventos, internacionais e nacionais, resultaram em debates e documentos norteadores da Educação Ambiental, que afetaram e afetam a relação entre sociedade e ambiente, assim como as construções de significados sobre os processos de Educação Ambiental. 
É evidente que as relações entre meio ambiente e indivíduo têm sido gradativamente transformadas e convertidas ao processo de modernização da sociedade.

A natureza e a cultura, fontes de vida, significação e potencial produtivo foram deslocadas pelo processo de globalização econômica que desencadeou um processo de degradação ambiental e destruição das formas de organização da vida e da cultura (LEFF, 2001, p. 285).

Refletir sobre as relações entre meio ambiente e cultura remete ao reconhecimento das experiências e conhecimentos construídos pelos indivíduos, o que refere-se à construção de valores e de sentidos. Para Leff, é necessário o resgate dos conhecimentos das comunidades, enfatizando seus valores e informações sobre as questões ambientais.

Tomando-se os pressupostos hegemônicos do campo da Educação Ambiental entende-se que esta volta-se para uma mudança de atitudes e hábitos do homem em relação ao meio no qual está inserido, que possibilite a construção de uma racionalidade ambiental, a qual implica a formação de um novo saber e a integração interdisciplinar do conhecimento (LEFF, 2001).

Dessa forma, associar os conhecimentos do cotidiano com os do contexto escolar, implica em mudanças e comprometimento por parte dos envolvidos nesse processo.

É hegemônico também entre autores e educadores que para o desenvolvimento de uma visão interdisciplinar, os educadores e as instituições precisam de uma profunda transformação nos modos de ensinar e aprender. As práticas interdisciplinares, que preparem indivíduos reflexivos e críticos, com uma visão global e integradora de ambiente, que possibilite 0 desenvolvimento da cidadania e a participação na resolução dos problemas ambientais é, ainda, uma utopia na Educação Ambiental.

Para além desta perspectiva que enfatiza o posicionamento politizado, surge outra, que propõe uma Educação Ambiental estética, vivencial, poética, experienciada com o corpo em contato com a natureza. Esta perspectiva é explorada de forma marginal nos documentos norteadores da Educação Ambiental brasileiros, mas é central nesta pesquisa, daí sua contribuição para o campo da Educação Ambiental.

\section{Por uma Educação Ambiental vivencial}

A perspectiva vivencial parte do pressuposto que a Educação Ambiental não deve apoiar-se apenas em conhecimentos transmitidos de forma tradicional, mas deve, por meio de um contato direto com o ambiente natural, com atitudes de respeito e cuidado, buscar construir uma verdadeira consciência ambiental. 
[...] pensaremos, sentados em nossa sala de aula, da mesma forma como se estivéssemos com os pés mergulhados em uma cristalina água de corredeiras? O que poderá ser mais provocador na busca da essencialidade do conhecimento do que uma caminhada reflexiva à mercê dos quatro elementos? (PERALTA, 2002, p. 116).

Os questionamentos do autor levam à proposta do desenvolvimento de aprendizados de Educação Ambiental nas escolas envolvendo um contato direto com a natureza, como uma maneira de estimular a percepção e interpretação ambiental dos alunos (PERALTA, 2002).

Uma autora que reflete sobre essa proposta de interação e vivências com a natureza é Mendonça. Seus estudos mais recentes estão voltados para Fenomenologia Goetheana, focada nas relações sociais e do diálogo. Sob esta perspectiva, a ciência e a estética estão claramente inter-relacionadas, já que se busca uma nova forma de conhecer e interagir com a natureza, ampliando e aprofundando o conhecimento do indivíduo, influenciando seu refletir e pensar. Em relação ao diálogo, sua natureza é exploratória, seu significado e métodos continuam a se revelar. Portanto ele é essencialmente integrado ao processo de aprendizagem - não como resultado do consumo de informações ou uma doutrina comunicada por uma autoridade, nem como meio do exame ou da critica a uma particular teoria ou programa, mas como parte de um processo de participação criativa entre pares que está em contínuo desenvolvimento, escreve Mendonça. Esta autora fundou o Instituto Romã, organização brasileira que divulga o método de vivências na natureza preconizado por Joseph Cornell (INSTITUTO ROMÃ, 2014)

Para Mendonça (2007), a escola tem trabalhado fortemente a transmissão dos conteúdos, baseada na possibilidade de conhecer sem vivenciar as informações e sem contextualizá-la, de modo que sejam transformadas em saber. A Educação Ambiental vivencial estabelece que o aprendizado seja realizado através do corpo, da percepção, dos sentidos, considerando assim o indivíduo de forma integral.

A Educação Ambiental vivencial baseia-se no estímulo ao contato direto com a natureza, buscando a reintegração do ser humano ao meio natural, tendo como objetivo uma consciência crítica e transformadora. Esse contato deve ser planejado objetivando despertar o reencantamento do ser humano pelo ambiente, promovendo assim uma mudança no comportamento dos envolvidos. Segundo a autora, as vivências possibilitam a construção de laços de cooperação e diálogo entre os participantes, decorrentes de seu agir e de reflexões coletivas.

[...] A educação vivencial é especialmente importante na Educação Ambiental, uma vez que esta última pretende lançar nos indivíduos a percepção de sua responsabilidade sobre o 
que acontece no mundo, e de sua participação num todo maior que inclui o passado, o presente e o futuro. Pretende, portanto, que os conceitos sejam internalizados e transformados em comportamentos inovadores e criadores de novos modos de viver, de novas culturas (MENDONÇA, 2007, p. 120).

As experiências de Educação Ambiental que estimulam os sentidos possibilitam ao ser humano novas formas de relação com o ambiente. "Sentir a natureza", também é uma proposta referenciada de modo tímido nos PCN's (1997), documento que aponta que através de uma educação vivencial o ser humano se reencantaria com a natureza.

A perspectiva vivencial estabelece que é necessário estimular a construção e reconstrução de novos sentidos sobre o ambiente, fazendo com que 0 indivíduo perceba-se como parte integrante e corresponsável, reaprendendo a "sentir a natureza".

Pensar e vivenciar atividades com a natureza é uma proposta desenvolvida por Joseph Cornell, educador naturalista. O termo vivências com a natureza foi definido para designar, em português, a expressão sharing nature $^{3}$. Cornell desenvolve, desde a década de 1970, atividades, jogos e exercícios que proporcionam uma aproximação e interação do indivíduo com o meio ambiente, propondo "processos de autoconhecimento, de abertura para a experimentação com os seres vivos e um profundo conhecimento e respeito pela natureza humana" (MENDONÇA, 2000).

À medida que começamos a sentir uma comunhão com os seres vivos que nos rodeiam, nossas atitudes tornam-se mais harmoniosas e fluem com naturalidade, e, por conseguinte, passamos a nos preocupar com as necessidades e o bem estar de todas as criaturas (CORNELL, 1997, p.13)

As atividades propostas pelo método de Cornell objetivam a ressignificação de sentimentos, desenvolvendo o respeito e admiração pela natureza. Assim, "cada brincadeira cria uma situação, ou uma experiência, na qual a natureza é a mestra" (CORNELL, 1996, p.4). Isto porque parte-se do pressuposto que, mesmo que necessárias, apenas as informações e conhecimentos são insuficientes para causar uma transformação na forma dos seres humanos se relacionarem com a natureza. É o equilíbrio entre o sentimento e a razão que proporcionaria o entendimento global da natureza (MENDONÇA, 2000).

\footnotetext{
${ }^{3}$ Sharing Nature, que, em inglês, significa "compartilhando a natureza" é o nome da fundação criada pelo educador naturalista Joseph Cornell, para indicar a filosofia e a metodologia por ele elaborada. No Brasil, seu representante é o Instituto Romã (www.institutoroma.com.br) que criou a versão para o português de sharing nature: Vivências com a Natureza.

Revbea, São Paulo, V.10, № 4: 58-78, 2015.
} 
As experiências com a natureza se agrupam a formas de perceber, sentir, compreender e vivenciar o universo, aposta Cornell, para quem o principal ingrediente para uma efetiva conservação dos espaços naturais é a afetividade. Seniciato e Cavassan (2008) concordam que toda aprendizagem tem uma dimensão afetiva, onde as emoções e anseios moldam as atitudes, as preferências e a motivação em aprender. Assim, no planejamento e execução das ações pedagógicas, entende-se que a afetividade interfere na construção de saberes e percepções voltadas ao meio ambiente.

Realizar atividades que envolvem um contato direto com a natureza, como tocar as plantas, cheirar as flores, ouvir os sons dos pássaros, são ações que desenvolvem a estimulação sensorial, despertando os sentidos que muitas vezes são ofuscados pela visão. Esta foi a perspectiva utilizada na pesquisa realizada na Escola Estadual Barão de Parima, em Boa Vista, Roraima.

\section{Método}

A abordagem é qualitativa, portanto considera o sujeito de estudo em determinada condição social, pertencente a um específico grupo social ou classe com suas crenças, valores e significados. Implica também considerar que o objeto das ciências sociais é complexo, contraditório, inacabado e está em permanente transformação, porque o ser humano envolve-se em uma multiplicidade de relações e interações (MINAYO et al., 2002). Para Silva e Menezes (2001, p. 20) "A interpretação dos fenômenos e a atribuição de significados são básicos no processo de pesquisa qualitativa. O processo e significado são os focos dessa abordagem".

Atuaram como informantes da pesquisa 12 alunos do $5^{\circ}$ ano do ensino fundamental e seus familiares. Quanto aos instrumentos empregados para a coleta de dados, utilizaram-se questionários estruturados antes das vivências e entrevistas semiestruturadas antes e após as vivências, a fim de verificar o incremento de sentidos após as vivências. Realizaram-se cinco encontros com atividades práticas referenciadas na proposta de Joseph Cornell, que consiste em quatro etapas e cinco regras, por meio das quais diferentes jogos e vivências estimulam os cinco sentidos. Dois encontros aconteceram na própria escola e três no Bosque dos Papagaios ${ }^{4}$, localizado no município de Boa Vista, Roraima.

Para analisar as construções sociais dos sujeitos participantes da pesquisa, coletadas nos questionários, entrevistas e nas vivências, foi utilizada a análise discursiva textual, a qual pode ser entendida como:

\footnotetext{
${ }^{4}$ O Parque Ecológico Bosque dos Papagaios é atendido pela Prefeitura de Boa Vista, em uma área de 12 hectares de conservação ambiental localizada em ambiente urbano. É a principal ferramenta pedagógica em ambiente natural de educação ambiental do município de Boa Vista/RR. O Bosque dos Papagaios possui mais de 20 espécies de árvores e 57 espécies de aves catalogadas. Possui seis trilhas, sendo duas ideais para caminhada e quatro educativas, que permitem aos visitantes percorrer seus cinco quilômetros em contato com a natureza.
} 
[...] um processo integrado de análise e de síntese, que se propõe a fazer uma leitura rigorosa e aprofundada de conjuntos de materiais textuais, visando descrevê-los e interpretá-los no sentido de atingir uma compreensão mais elaborada dos fenômenos e dos discursos no interior dos quais foram produzidos (MORAES, 2007. p 89).

As análises focaram as vivências relacionado-as aos significados que emergiram dos questionários e entrevistas que foram se mostrando pertinentes à análise. $\mathrm{A}$ identidade dos participantes foi preservada, atendendo-se, desta forma, a critérios éticos. A pesquisa de campo durou 12 meses, finalizando em novembro de 2013.

\section{Vivências na natureza: o método}

Para propor momentos de exploração com a natureza, proporcionando aos alunos ocasiões alegres e gratificantes, Cornell (1996) criou cinco regras de ensinamento ao ar livre.

A primeira regra apresentada por Cornell se traduz em ensinar menos e compartilhar mais, considerando a importância de se compartilhar sentimentos e pensamentos, incentivando a criança a explorar respeitosamente suas emoções, criando assim, uma relação de confiança e companheirismo. Perceber a importância da receptividade é outra regra, em que ser receptivo significa ouvir e estar atento, pois as atividades ao ar livre provocam um entusiasmo espontâneo nas crianças, e, com aptidão o professor poderá direcioná-lo para o aprendizado. Outra regra é a busca pela concentração e atenção da criança, levando-a a sentir a importância de suas descobertas. Observar, sentir e falar são três ações que correspondem a quarta regra sugerida por Cornell, visando atender à necessidade de o aluno sentir-se parte e em harmonia com a natureza. Já a última regra é o clima de alegria, que deve prevalecer durante o desenvolvimento das atividades, nas quais 0 entusiasmo do professor deve ser contagiante, transformando-se assim na sua arma mais poderosa (CORNELL, 1996).

Partindo dessas regras e no desenvolvimento de atividades relacionadas à natureza, Cornell compreendeu que para que os jogos e brincadeiras fossem mais produtivos, independente da idade e estado de espírito dos participantes, era necessário organizar uma sequência, denominada por ele de método de Aprendizado Sequencial. "O método de aprendizado sequencial não se restringe apenas no estudo com a natureza - é também uma técnica maravilhosa de ensino para muitas outras matérias" (CORNELL, 2008, p.59).

Tal método está dividido em quatro fases que incluem diferentes jogos, por meio dos quais são trabalhados os cinco sentidos: a primeira visa despertar o entusiasmo; a segunda busca concentrar a atenção dos alunos; já a terceira 
dirige a experiência; enquanto na quarta fase se compartilha a inspiração. Descreve-se, a seguir cada uma dessas fases.

A primeira, como o nome sugere, Despertar o Entusiasmo é uma fase que se propõe mais fortemente a ser divertida. Nesse sentido, as brincadeiras e atividades são repletas de alegria gerando, assim, um fluxo grande de energia. Nessa fase, deve-se criar uma atmosfera de entusiasmo e vivacidade, possibilitando, assim, a construção de experiências de aprendizagem sutis e significantes (CORNELL, 2008).

No final dessa etapa, as pessoas, em geral se divertiram muito e estão se sentindo relaxadas e entusiasmadas, além de entrosadas. A partir daí devese conduzir essa energia para uma Atenção Concentrada, segunda fase descrita por Cornell. As atividades realizadas nessa fase ajudam as pessoas a se tornarem mais observadoras além de harmonizar coração e mente com as belezas da natureza (CORNELL, 2008). À medida que se vai concentrando a atenção, pouco a pouco, os participantes se tornam mais conscientes de que estão tocando, vendo, cheirando, degustando e ouvindo, estímulos esses, recebidos do meio e da intuição, o que desperta uma tranquilidade interior e permite experienciar com a natureza, remetendo assim à terceira fase que é Conduzir a experiência. Nessa fase, as pessoas aprendem melhor a partir de suas próprias descobertas pessoais, o que se pressupõe que favoreça 0 comprometimento com ideais ecológicos.

Ao final da terceira fase, os participantes sentem-se tranquilamente alegres, prontos para ouvir histórias. Assim, na quarta e última fase do aprendizado sequencial ocorre o Compartilhar a inspiração, momento em que as pessoas relatam as experiências que tiveram no decorrer das atividades. Compartilhar reforça o sentimento de encantamento e faz com os participantes criem vínculos entre si. As atividades dessa fase proporcionam também o encerramento das atividades, oferecendo uma sensação de totalidade. "O aprendizado sequencial permite criar inúmeras variações de experiências com a Natureza, sendo cada uma delas única e perfeitamente adequada à situação do momento" (CORNELL, 2008, p.32).

A vivência é essencial para que o processo do Aprendizado Sequencial seja realizado com sucesso, sendo a experiência importante para a sua compreensão. Ao caminhar pelos espaços naturais, o educador proporciona momentos em que cada um sente-se observando o meio e, também, a si mesmo em relação com os demais.

O aprendizado sequencial tem por objetivo proporcionar uma experiência genuinamente positiva com a natureza. Depois de uma sessão conduzida com sucesso, cada participante adquire uma nova, agradável e sutil conscientização de sua unidade com a natureza e uma intensa empatia com a vida. Você também descobrirá que as pessoas participarão com mais entusiasmo das discussões sobre 0 aspecto científico da história natural e da ecologia se você primeiro ajudá-las a ficar receptivas e inspiradas (CORNELL, 1997, p.17-18) 
As informações e conhecimentos e, principalmente as vivências, tornam-se essenciais para uma transformação na forma como cada um se organiza e se relaciona com o mundo, proporcionando um equilíbrio entre a razão e o sentimento, para um entendimento integral da natureza (MENDONÇA, 2000).

\section{Vivências na natureza: análises empíricas}

$\mathrm{Na}$ tentativa de estimular a percepção das crianças a partir da proposta vivencial foram desenvolvidas atividades lúdicas, relacionando-as aos conteúdos curriculares: Morcego-Mariposa, Coruja e Corvos, Encadeamento, Passeio da Lagarta, Arca de Noé Tons de Verde, Que Animal Sou Eu, Predador e Presa, Silhueta das Árvores, Construir uma Árvore e Animal Misterioso. Nestas atividades os conteúdos e conhecimentos previstos nos currículos foram abordados pelo método das vivências na natureza. A seguir se descrevem as atividades e como foram exercitadas, para posteriormente se analisar a emergência de sentidos.

A atividade "Morcego e Mariposa" foi desenvolvida no Bosque dos Papagaios. Trabalharam-se os hábitos dos animais e o sentido da audição. Foi solicitado que fizessem um círculo e que cinco crianças participassem (uma como morcego e as outras no papel de mariposa). Os demais representariam a floresta. Foram vendados os olhos dos cinco alunos e as mariposas repetiam o nome do animal que estava representando. Através do som, o morcego devia perseguir e pegar as mariposas. Como os olhos foram vendados, o objetivo era que a audição fosse mais utilizada nesse momento.

Nesta atividade, inicialmente, percebeu-se uma agitação e dificuldade de concentração por parte das crianças. Todos estavam entusiasmos e queriam participar da atividade, sendo necessário repeti-la cinco vezes para que todos pudessem participar. Emergiu um sentimento de cooperação entre as crianças, pois quando não estavam sendo morcego e mariposa, os demais ficavam em silêncio, facilitando a localização das marioposas pelo morcego. Este sentido evidenciou-se na fala de um aluno5: "Vamos ficar em silêncio, o morcego precisa pegar a mariposa" (A3).

Essa atividade vivencial permitiu a construção de atitudes coletivas e de diálogo, quando interesses e ideias são compartilhados. No momento de compartilhamento da inspiração, refletiu-se sobre conceitos, tais como seleção natural, predador e presa, hábitos noturnos do morcego, bem como 0 desenvolvimento da audição e a necessidade da concentração. Percebeu-se um interesse dos alunos em entender as características e hábitos do morcego.

O jogo "Corujas e Corvos" busca Despertar o Entusiasmo. As crianças foram divididas em duas equipes (uma de corujas e a outra de corvos). As

5

A identificação dos alunos no texto foi realizada através da letra $A$ seguido de um Revbea, São Paulo, V.10, № 4: 58-78, 2015. 
equipes foram alinhadas de frente uma para a outra, distantes cerca de um metro. Em seguida, explicou-se como seria o jogo. Foram ditas algumas frases referentes à natureza e ao Rio Branco (principal rio de Boa Vista). Quando as frases eram consideradas verdadeiras as corujas deveriam correr atrás dos corvos, quando falsas os corvos deveriam correr atrás das corujas. Aquele que fosse pego passaria para o lado oposto. ${ }^{6}$

Com a realização dessa atividade percebeu-se três comportamentos nas crianças: a curiosidade, a ansiedade e a competitividade. A curiosidade e a ansiedade foram percebidas já no momento em que se explicava como a atividade seria desenvolvida, pois as crianças faziam perguntas e queriam logo saber o que iriam fazer, o que prejudicou alguns alunos, que não conseguiram prestar atenção nas perguntas feitas e, por isso, foram capturados com facilidade pelo grupo contrário. Como o objetivo do jogo era que um grupo capturasse 0 outro, a competitividade revelou-se entre os alunos, pois começaram a contar quantos estavam em cada grupo.

No compartilhamento os alunos demonstraram que as questões ajudaram a refletir sobre características do lugar onde vivem, o que despertou a sensação de fazer parte desse espaço. Esta vivência gerou a participação dos alunos de uma maneira significativa diante do tema proposto nas questões.

A atividade "Encadeamento" buscava Despertar o Entusiasmo. As crianças formaram um círculo. A pesquisadora ficou dentro do círculo com o rolo de barbante na mão, fazendo perguntas. A medida que cada criança ia respondendo recebia o rolo de barbante, de modo que todos ficaram interligados. Objetivando demonstrar que, como num ecossistema, um elemento depende do outro para a sobrevivência. No final da atividade, após todas as perguntas terem sido feitas, foi retirado um elemento do conjunto, no caso uma árvore de Roraima foi cortada. Desta forma, o aluno que representava a árvore caiu e arrastou consigo o barbante, fazendo com que muitos alunos sentisse o "puxão" por causa da morte da árvore. ${ }^{7}$

No final da atividade, foi realizada uma roda de compartilhamento para que os alunos falassem sobre o que tinha acontecido com a árvore e de que forma a morte de um elemento da natureza pode afetar os demais. O relato de

\footnotetext{
${ }^{6}$ As frases utilizadas foram: O rio Branco é o maior rio do Estado de Roraima (v); Tem tubarão no Rio Branco (f); As árvores são seres vivos (v); O leão é encontrado na savana de Roraima (f); A água que vem da sua torneira é do Rio Branco (v); Quando chove muito o rio esvazia (f); O Rio Branco é importante para o município de Boa Vista (v); As árvores nos dão oxigênio (v); Em Roraima temos as quatro estações definidas (f); Os maiores rios que formam o Rio Branco são o Tacutu e Uirariquera (v); O monte Roraima faz divisa com os países: Brasil, Venezuela e Suriname (f).

${ }^{7}$ As perguntas feitas foram: - uma fruta típica de Roraima; - uma etnia indígena de Roraima; - um peixe existente no estado de Roraima;- um município de Roraima; - o município que faz fronteira com a Venezuela; - uma árvore em Roraima; - o que faz fronteira com a Guiana; - o município com maior número de indígena de Roraima; - um ponto turístico de Boa Vista; - uma comida típica de Roraima;- algo necessário para sobrevivência dos seres vivos; - um bairro de Boa Vista; - um animal encontrado na savana de Roraima.
} 
um aluno sintetiza o sentido despertado pela atividade: "Devemos fazer alguma coisa pelo meio ambiente" (A7).

Os alunos mostraram-se preocupados com o meio ambiente e alguns relataram a vontade de fazer "alguma coisa" para salvá-lo. Evidenciou-se, nesse momento, que as crianças assumiram um sentido de responsabilização com o ambiente. Não apenas no sentido de tirar o meio ambiente da situação de perigo, mas também de dar condições para que a natureza se revele a partir da ação humana. Salvar, neste sentido, aponta que o desenvolvimento da atividade proporcionou também uma reaproximação respeitosa com a natureza. Além disso, as crianças puderam conhecer um pouco mais sobre aspectos ambientais do seu estado e entender as dinâmicas de um ecossistema.

Apesar de ansiosos para realizar a atividade, os alunos mostraram-se atentos para saber o que iria acontecer naquele jogo. Observou-se, também, um desassossego com as atividades ao ar livre, que não acontecem na escola. O Bosque dos Papagaios é um espaço natural da cidade pouco frequentado pela escola. Apenas dois alunos conheciam o local, conforme informado por eles.

Nestas atividades também observou-se que a brincadeira efetivamente funciona como uma estratégia para despertar a receptividade, aumentando o envolvimento dos participantes com a proposta feita pelo mediador e dos participantes entre si.

Da mesma forma, percebeu-se que o sujeito, ao ser inserido em situações desafiadoras com o meio ambiente, observa, reage e responde por meio de suas percepções, processos cognitivos, julgamentos e expectativas. Essas manifestações foram evidenciadas na atividade "Passeio da Lagarta".

Com o objetivo de concentrar a atenção, solicitou-se que as crianças se posicionassem em uma fila. Seus olhos foram vendados e elas fizeram um percurso já demarcado com um barbante, exercitando os demais sentidos ao perceber cheiros, sons, brisa. No final, os alunos foram levados a um local onde ficaram em círculo em formato de caracol, agachados e bem encolhidos. Então foi dado o comando para que abrissem os braços, mexendo-os, imitando assim, a transformação da lagarta em borboleta. Logo após, eles tiraram as vendas dos olhos e refletiu-se sobre a metamorfose da borboleta (ovos lagarta - casulo - borboleta).

As crianças expressaram terem vivido um sentimento de medo, porque os olhos ficaram vendados. Este sentimento pode ter representado a individualização em um processo de afirmação do sujeito num contexto coletivo. Ou seja, os olhos vendados possibilitaram a experiência do "eu" com o "meio" numa relação de isolamento, de enfrentar, por meio dos demais sentidos, o que a visão não alcançou, conforme relatado por A3: "Eu senti um pouco de medo [...] mas depois passou". Essa ruptura visual causou insegurança, mas também proporcionou um encontro com outras percepções e 
um envolvimento com a natureza, conforme os relatos: "Eu consegui ouvir os pássaros" (A9); "Nossa! O canto dos pássaros é bem legal” (A1).

Nos relatos que emergiram a partir das vivências evidenciou-se a importância das experiências sensoriais em espaços naturais, que transcendam os "muros das escolas", experienciando outros contextos de aprendizagem, o que favorece a construção de novas interpretações e significados, que enriquecem o desenvolvimento humano. Com essa atividade buscou-se desenvolver a habilidade de "enxergar" outras possibilidades de contato com a natureza e, com isso, observou-se também o desenvolvimento da atenção.

Com a atividade a "Arca de Noé" o intuito era refletir sobre os diversos tipos de animais existentes, bem como os movimentos e sons que os mesmos fazem, em uma atividade que despertasse o entusiasmo. Os alunos formaram um círculo e foi entregue uma ficha para cada um, na qual leram o nome do animal que estava escrito e guardaram segredo. Havia sempre dois animais repetidos. Em seguida, os alunos começaram a imitar o animal descrito na sua ficha, apenas com gestos e sons. Os pares foram se encontrando e continuaram gesticulando e emitindo sons, de modo que, ao final, voltou-se ao grande círculo e cada dupla representou o seu animal para que os demais adivinhassem.

Os pares foram se encontrando com facilidade devido aos gestos e sons feitos pelos alunos, porém percebeu-se que alguns alunos, principalmente as meninas, demonstraram um pouco de timidez. Questionados, afirmaram que sentiam vergonha de imitar os animais. Isso pode caracterizar o não desenvolvimento de atividades que utilizam o corpo para se expressar. No entanto, alguns alunos começaram a imitar os animais representados pelos colegas, ajudando assim aquelas que demonstravam timidez.

A atividade intitulada "Tons de Verde" buscou Concentrar a Atenção. Foi escolhido dentro do Bosque dos Papagaios um local com muitas árvores. Solicitou-se às crianças que observassem os vários tons de verde existentes, as formas e os detalhes de cada árvore. No decorrer dessa atividade as crianças mostraram-se concentradas e, em alguns momentos, o silêncio tomou conta do local, gerando uma sensação de paz e tranquilidade.

Ao proporcionar momentos de contemplação da natureza, os alunos puderam desenvolver a atenção e habilidades sensitivas em interação com a natureza. É o que se percebe no relato do aluno: "Foi bom olhar para a natureza sem pensar em nada" (A7).

Ao final, cada criança socializou sua experiência, relatando quantos tons tinha encontrado: de vinte a cinquenta. Diante da atividade, algumas falas significativas se destacaram: "Já pensou se tivéssemos que olhar o bosque todo? Seriam milhares de tons, é muito bonito" (A5); "A natureza é mesmo perfeita" (A8). No relato do A5, evidencia-se que a atividade proporcionou ao aluno uma visão mais ampla do contexto em que ele se encontrava naquele momento. 
O objetivo da atividade "Que Animal Sou Eu" foi Despertar o Entusiasmo. Colou-se nas costas de cada criança a figura de um animal. Em dupla, cada colega fazia perguntas ao outro relacionadas às características do animal que representava, a fim de descobrir sua identidade. As respostas deveriam ser apenas sim, não e talvez. O desenvolvimento da atividade gerou um clima de descontração e envolvimento. Alguns alunos sentiram um pouco de dificuldade para descobrir o seu animal, pois não conseguiam elaborar questões relativas às características (voa? tem patas?). A medida que os alunos iam descobrindo os seus animais, eram enfatizadas as suas características, alimentação e hábitos.

A maioria disse ter gostado da atividade, identificando as características dos animais presentes na brincadeira e demonstrando conhecimento de quais eram presentes na fauna do Estado. No entanto, chamou a atenção o relato de um aluno quando disse: "Eu gostei aqui do Bosque, cheguei a esquecer lá da escola" (A7).

Infere-se, a partir desse relato, que o desenvolvimento de práticas pedagógicas em espaços naturais pode constituir um relacionamento intenso com o meio ambiente, gerando respostas sensoriais e afetivas significativas, inclusive ressignificando as práticas realizadas na escola. $O$ ato de esquecer "lá da escola" pode ser compreendido como uma necessidade de abordar a questão ambiental de forma mais significativa. Também indica a necessidade de se (re)pensar o aprendizado escolar sobre as relações do homem com a valorização dos elementos emocionais e naturais.

A atividade "Predador e Presa" buscou Despertar o Entusiasmo. Os alunos formaram um círculo e foi solicitada a participação de três crianças (uma foi o predador e as outras duas foram as presas). As crianças escolheram os animais. Como predadores definiram o homem, a onça e a cobra. Os escolhidos para serem as presas foram a vaca, o capim, o gato do mato, o rato, o sapo e a mosca. Os olhos dos participantes foram vendados e foi colocado em seus corpos um sinalizador de som, de modo que o predador poderia localizar as presas apenas através do som que elas faziam.

As atividades decorreram com descontração e muito riso devido ao som dos sinalizadores e à empolgação do predador em capturar as presas. Além da audição, o tato foi um sentido utilizado pelo predador no decorrer dessa atividade. Com as mãos ele tentava capturar as suas presas. No final dessa atividade foram compartilhadas as percepções deles diante da atividade, destacam-se os fragmentos: "Tive medo quando fui a 'presa'. Não queria ser pega" (A9); "Se o gato não comer o rato, e a cobra não comer o sapo, eles vão ficar com fome" (A5); "Um ajuda o outro na hora de comer" (A2).

Diante dos relatos observa-se que colocar-se na posição de "presa" é assumir uma vulnerabilidade diante desse ciclo da cadeia alimentar. Por outro lado, evidencia-se nas falas de A5 e A2, a compreensão da inter-relação entre as espécies na formação da cadeia alimentar, e a importância desta para 0 
equilíbrio do meio ambiente. Também observou-se uma reflexão sobre a relação de ameaça entre as espécies.

$\mathrm{Na}$ atividade "Silhueta das Árvores", em grupo, os alunos escolheram uma árvore que lhes tivesse chamado a atenção, observaram e, em seguida, imitaram-na para os colegas. A natureza é composta de vários tipos diferentes de árvores, com várias formas, tamanhos e cores. Com o desenvolvimento dessa atividade estimulou-se a percepção da particularidade de cada árvore, assim como a criatividade e imaginação para a sua imitação.

Inicialmente percebeu-se uma euforia por parte dos alunos, pois estavam indecisos na escolha da árvore que iriam representar, o que foi controlado quando as escolhas foram realizadas. Essa vivência possibilitou aos alunos um momento de encontro consigo e com o outro, de cuidar de si e olhar para o outro. No momento da socialização de suas escolhas, as crianças precisaram utilizarem seus corpos, mais especificamente pernas e pés para representar as raízes e os braços como os galhos. Um aluno deitou-se no chão representando a raiz da árvore. Esta atividade proporcionou aproximação entre os alunos e a desinibição daqueles que se mostravam tímidos.

"Construir uma árvore" foi uma atividade que teve como objetivo Despertar o Entusiasmo. As crianças foram questionadas sobre as partes de uma árvore, conteúdo que já haviam estudado em aula. Foi solicitado que formassem dois grupos e que com o corpo representassem galhos, tronco, raiz e folhas. Essa atividade foi caracterizada pelo dinamismo e pela revisão dos conteúdos já aprendidos em sala de aula, desta vez por um método lúdico. Isso se revela na fala de um aluno: "Essa atividade é legal: representar as partes de uma árvore com o nosso corpo" (A6).

O aluno A6 percebeu-se como um integrante do meio natural, portanto a atividade pode ter provocado um processo de inserção do indivíduo na natureza, estimulando a se (re)definir como parte do ecossistema. Refletiu-se nesse momento sobre a importância que cada parte da árvore tem no processo de desenvolvimento e sua função na natureza.

A atividade "Animal Misterioso" teve o objetivo de conduzir a Experiência Direta. Em grupo, os alunos escolheram um animal que deveriam representar com seus corpos. Os alunos mostraram-se entusiasmos em apresentar e em ver a apresentação dos colegas. Sua criatividade foi evidenciada através dos gestos e sons que encontraram para representar o animal escolhido: o rugido do leão ou o canto do tucano, por exemplo. Os alunos se envolveram na atividade e se divertiram com os modos de representação corporal. Após, fez-se uma socialização das características dos animais representados, como sua alimentação, tipo de cobertura e sons.

A análise da descrição das atividades de vivências na natureza deixaram emergir emoções e sentidos diversos, conforme o grupo evoluía nos encontros e conforme as atividades propostas: agitação, dificuldade de concentração, concentração, entusiasmo, cooperação, interesse, ansiedade, competitividade, participação, atenção, desassossego, medo, preocupação, 
responsabilização, informação, interrelação, vínculos, envolvimento, receptividade, isolamento, insegurança, riso, dificuldade, timidez, solidariedade, sensibilidade, cuidado, reflexividade, tranquilidade, desenvolvimento de habilidades, ampliação da percepção, sentir-se parte, diversão, dinamicidade, descontração, curiosidade, afetividade, intensidades, empolgação, percepção da vulnerabilidade da vida, criatividade, euforia, socialização, indecisão e encontro consigo, com seu corpo, com o outro, com o ambiente natural. Estas potencialidades emergiram em processos educativos voltados para um público inserido no contexto educativo formal. Também os alunos afirmaram que as atividades despertaram sentimentos específicos em relação aos colegas quando participaram das vivências: companheirismo, união, respeito, alegria, educação, amizade, alegria e satisfação.

Uma análise de conteúdo dos pressupostos teóricos e estudos empíricos do campo da educação colocam estas mesmas palavras que emergiram da observação analítica das vivências como características de algo que ainda desafia as práticas escolares. Portanto, esta pesquisa evidencia que o método das vivências no âmbito da educação contribui na resolução do que hoje se constitui um problema do campo: a falta de entusiasmo e envolvimento dos atores envolvidos no processo educativo.

Obviamente este estudo tratou da temática ambiental, mas outros temas podem ser abordados tendo o ambiente natural, ao ar livre, como contexto físico e operacional de aprendizagem. Cornell (1997) afirma que o desenvolvimento de sentimentos de afetividade e de preocupação para consigo, com os outros e para com a natureza é a base para a construção de um processo educativo.

Ao realizar-se o cruzamento dos resultados obtidos por meio dos questionários e entrevistas com os sentidos que emergiram atividades desenvolvidas em cinco encontros com os alunos, observou-se uma mudança de atitude assumida por eles, percebida não só pela pesquisadora, mas também pela professora regente da sala, a qual afirmou que os alunos mostraram-se mais envolvidos e participativos em aula, (re)afirmando responsabilidades e compromissos relacionados à questão ambiental, o que vai ao encontro da hipótese de Cornell, quando pressupõe que o método das vivências favorece o comprometimento ideológico.

A Educação Ambiental que objetiva o desenvolvimento de habilidades, a fim de transformar as atitudes do ser humano em relação ao meio, utilizandose dos métodos tradicionais (que hegemonicamente vêm sendo utilizados pela escola) dificilmente tem conseguido atingir resultados que potencializem seres sensíveis. Mais facilmente se pode obter alguns relatos "conscientes" da problemática ambiental em relação à plantas, animais, água, resíduos e mudanças climáticas, pois, assim, como os métodos, estes são os temas hegemônicos nas escolas.

O aprendizado sequencial por meio das vivências estabelece-se, ao mesmo tempo, como um retorno do ser humano ao contato primordial com a 
natureza e como uma tendência contemporânea, que tem como fim um aprendizagem autêntica.

No aprendizado vivencial, é o corpo inteiro que aprende, não só o cérebro, e ele aprende por que interage com o que deve ser aprendido. As vivências permitem que a pessoa se aproxime de si mesma, fazendo com que o aprendizado se torne autêntico, pois é seu próprio corpo que vai produzir o conhecimento (MENDONÇA, 2007, p.10).

A aprendizagem autêntica, para Mendonça (2007) caracteriza-se pela participação integral do sujeito na construção do conhecimento e descaracteriza a forma de transmissão dos conteúdos passados pela escola no formato de educação tradicional, no qual o processo de ensino-aprendizagem fundamenta-se na possibilidade de conhecer sem vivenciar, ou seja, sem se envolver com o conhecimento, criando um sistema educacional formal muito complexo e extenso em conteúdo. Essa mesma autora, afirma que no desenvolvimento de projetos aplicados na escola, costuma-se trabalhar com conceitos, proposições e comparações, porém esses instrumentos não despertam nos alunos novas percepções e novos sentimentos. Opondo-se a essa perspectiva, a educação vivencial:

[...] pode abrir oportunidades para fazer emergir novos sentimentos sobre novas relações, conduzindo às formas inovadoras de pensar, abrindo espaços para ações criativas e transformadoras. Se a vivência for positiva, bem elaborada e conduzida, pode deixar no indivíduo a convicção, percebida corporalmente, de que a construção de novas relações com o mundo é possível e, de que as raízes dessa construção, encontram-se nele mesmo, na memória corporal da experiência que teve, adquirindo assim, uma maior autonomia para pensar sobre si mesmo e seu estar no mundo, empoderando-se para observar suas limitações $e$ os pressupostos que subsidiam suas ações (MENDONÇA, 2007, p.121).

Observou-se, por meio das atividades sequenciais realizadas a partir desta pesquisa, que os alunos depararam-se com aspectos sutis, comprovando que a proposta sequencial baseada em vivências é um método despertador de novos sentidos e sensibilidades:

[...] tornam-se uma experiência de possibilidades de movimentos externos e internos, de explorações objetivas e subjetivas, de sensações e experiências cognitivas e afetivas suficientemente capazes de proporcionar a busca de novas 
situações onde respeito à Natureza, a si e ao outro, com a observância de valores relativos à cooperação, companheirismo, solicitudes, limitações e especialidades, disposição proativa, convivência com as diferenças pessoais, constituem-se em marcas e exercícios constantes durante todas as séries de atividades ao longo de seu percurso (GUIMARÃES, 2006, p.6).

As interações que se estabeleceram nas atividades vivenciais permitiram abordar o sujeito na sua imediata presença com o meio ambiente, mediada "pela emoção e pelo sentimento" (MUNHOZ e MAZZARINO, 2015).

\section{Considerações finais}

Todas as atividades de vivências realizadas neste estudo tiveram o propósito de despertar e aflorar o sentimento de pertencimento e amor pela natureza, além de estimular os sentidos e a percepção. Por esse motivo, utilizou-se a proposta do Aprendizado Sequencial. Segundo Cornell (1996) essa proposta orienta o professor-coordenador da atividade a partir de onde os alunos estão, para, então, despertar e guiá-los, passo a passo, por uma atividade de crescente sensibilização e um mergulho profundo na percepção e compreensão do meio ambiente.

As práticas vivenciais desenvolvidas durante esta pesquisa remetem a momentos de ressignificação, rupturas e produção de sentidos. Ao se fazer a reflexão acerca das atividades sequenciais desenvolvidas, analisa-se que as experiências com essa proposta mostraram que, além dos conhecimentos sobre a natureza e seus mecanismos, adquiridos pelo simples contato, surgiram novas formas de compreender, perceber e vivenciar o meio ambiente. Nesse sentido, a ênfase nos aspectos afetivos do processo ensinoaprendizagem, no qual o sentir tem um importante papel, permitiu a (re)descoberta da vida na natureza. Os cheiros, as nuances, as texturas do meio ambiente, muitas vezes pouco percebidos no cotidiano, tornaram-se elementos presentes na trajetória do sujeito. Ao experimentar situações, possibilitou-se aos alunos que elaborassem formas de pensar a partir do vivenciado.

Esta experiência vivida com os alunos tinha como objetivo a pesquisa de um processo, no entanto, o uso do método sequencial baseado nas vivências deve levar em conta a necessidade de continuidade, pressuposto básico de qualquer processo de Educação Ambiental, independente do método.

As experiências geradas e vivenciadas em uma atividade educativa ao ar livre, só não se diluem ou se dissipam se os processos capazes de gerar vínculos, continuidade e aprofundamentos reflexivos forem considerados e estabelecidos. Isso implica a necessidade de se conceber mecanismos e providências capazes de "contribuir para a 
superação da fragmentação dispersiva e do pontualismo estático que ocasiona esgotamento das atividades em si mesmas, de forma que as experiências produzidas possam conduzir a outras experiências e a outras situações qualitativamente crescentes" (PEGORARO, 2007, p.78).

Enfim, percebeu-se também que os alunos se sentiram efetivamente parte do meio em que vivem, demonstrando também preocupação com o futuro do ambiente natural, o que remete à conclusão que a exploração de estratégias lúdicas e estéticas na Educação Ambiental podem se reverter em processos de politização para pensar a relação entre sociedade e natureza.

Entende-se que é preciso deixar claro que considera-se que as abordagens de viés poético constituem-se como uma via de entrada para o processo de uma educação sensível, que pode vir a desencadear processos de politização em relação à problemática ambiental. Pode vir, mas este não se coloca como um objetivo das vivências. O objetivo das vivências é, em si mesmo, experimentar sentir-se em sua naturalidade. $O$ que gera assombros em tempos que nos encontramos cada vez mais distantes dos ambientes naturais. Estranhamentos estes que também emergiram nas falas, como se pode verificar.

\section{Referências}

BRASIL. Constituição da República Federativa do Brasil. Texto Constitucional de 05 de outubro de 1988, com as alterações adotadas pelas emendas constitucionais n.1, 1992, a 32, de 2001, e pela emenda constitucional de revisão n.1, a6, de 1994. ed. 17, Brasília: 1988, 405p.

BRASIL. Parâmetros curriculares nacionais: meio ambiente e saúde. Ministério da Educação e do Desporto. Secretaria de Educação Fundamental. 3. Ed. Brasília: SEF, 1997, v. 9.

BRASIL. A Implantação da Educação Ambiental no Brasil. Ministérios da Educação e do Desporto. Coordenação de Educação Ambiental. Brasília - DF, 1998.

BRASIL. Política Nacional de Educação Ambiental. Lei 9795 de 1999. Disponível em <http://www.planalto.gov.br/ccivil 03/leis/19795.htm>. Acesso em 07 abr. 2013.

CARVALHO, I.C.M. Educação Ambiental: a formação do sujeito ecológico. São Paulo: Cortez, 2012.

CORNELL, J. Brincar e aprender com a natureza: guia de atividades infantis para pais e monitores. São Paulo: Melhoramentos,1996.

CORNELL, J. A alegria de aprender com a Natureza. São Paulo: Melhoramentos, 1997.

CORNELL, J. Vivências com a Natureza 2. São Paulo: Aquariana, 2008. 
GUIMARÃES, S.T. Trilhas Interpretativas e Vivências na Natureza: reconhecendo e reencontrando nossos elos com a paisagem. Rio de Janeiro, 2006, p.01-17 Disponível em: <http://www.ambiente.sp.gov.br/cea/files/2011/12/Solange Guimaraes01.pdf> Acesso em: 27 fev. 2014.

INSTITUTO Romã. Disponível em: <http://www.institutoroma.com.br/>. Acesso em: 10 fev. 2014.

LEFF, E. Saber Ambiental: Sustentabilidade, Racionalidade, Complexidade, Poder. Petrópolis: Vozes, 2001.

LOUREIRO, C.F. Trajetória e Fundamentos da Educação Ambiental. São Paulo: Cortez, 2004.

LOUREIRO, C.F. Educar, participar e transformar em Educação Ambiental. Revista Brasileira de Educação Ambiental. vol 0, p.13-20, nov. 2004.

MENDONÇA, R. A experiência na natureza segundo Joseph Cornell: $A$ educação pelas pedras-ecoturismo e Educação Ambiental. Célia Serrano (org.) São Paulo: Chronos, 2000.

MENDONÇA, R. Educação Ambiental Vivencial. In: ENCONTROS e caminhos: formação de educadoras(es) ambientais e coletivos educadores. Vol. 2, p.119-129, 2007.

MINAYO, M.C.S. (org.) Pesquisa Social: teoria, método e criatividade. 21 ed. Petrópolis: Vozes, 2002.

MORAES, R. Mergulhos discursivos: análise textual qualitativa entendida como processo integrado de aprender, comunicar e interferir discursos. In: GALIAZZI, M.C.; FEREITAS, J.V. (orgs.). Metodologias emergentes de pesquisa em Educação Ambiental. ljuí: Unijuí, 2007.

MUNHOZ, A.V.; MAZZARINO, J. Conhecer não é representar: reflexões sobre a representação na Educação Ambiental. Perspectiva, Florianópolis, v. 31, n. 3, p. 1005-1020, mar. 2014. ISSN 2175-795X.

PEGORARO, J.L. Programas educativos junto à "natureza" e a Educação Ambiental. Anais do IV Encontro de Pesquisa em Educação Ambiental. Rio Claro: USP/UNESP/UFSCar, 2007.

PERALTA, C.H.G. Experimentos educacionais: eventos heurísticos transdisciplinares em Educação Ambiental. In: RUSCHEINSKY, A. (Org.). Educação Ambiental: abordagens múltiplas. Porto Alegre: Artmed, 2002.

SAITO, C.H. Política Nacional de Educação Ambiental e Construção de Cidadania: desafios Contemporâneos. In: RUSCHEINSKY, A. (Org.). Educação Ambiental: abordagens múltiplas. Porto Alegre: Artmed, 2002.

SENICIATO, T. CAVASSAN, O. Afetividade, motivação e construção de conhecimento científico nas aulas desenvolvidas em ambientes naturais. Ciências \& Cognição. Rio de Janeiro, v. 13 (3), p. 120-136, 2008.

SILVA, E.L.; MENEZES, E.M. Metodologia da pesquisa e elaboração de dissertação. 3ed. Florianópolis: Laboratório de Ensino a Distância da UFSC, 2

Qevbea, São Paulo, V.10, № 4: 58-78, 2015.

0 